\title{
Isolation and Characterization of an Eosinophilic GH $16 \beta$-Agarase (AgaDL6) from an Agar-Degrading Marine Bacterium Flammeovirga sp. HQM9
}

\author{
Yan Liu' ${ }^{1}$ Xiaoxu Tian ${ }^{2}$, Chao Peng ${ }^{2}$, and Zongjun $\mathrm{Du}^{1 *}$ \\ ${ }^{1}$ College of Marine Science, Shandong University, Weihai 264209, P.R. China \\ ${ }^{2}$ National Facility for Protein Science in Shanghai, Zhangiiang Lab, Shanghai, 201210, P.R. China
}

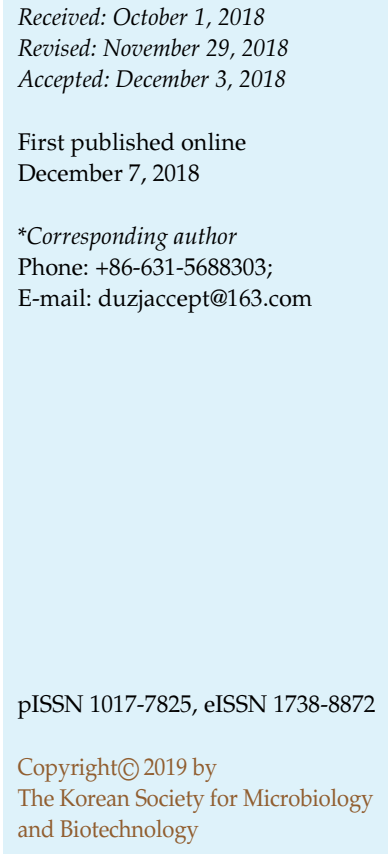

A special eosinophilic agarase exo-type $\beta$-agarase gene, AgaDL6, was cloned from a marine agar-degrading bacterium, Flammeovirga sp. HQM9. The gene comprised 1,383-bp nucleotides encoding a putative agarase AgaDL6 of 461 amino acids with a calculated molecular mass of $52.8 \mathrm{kDa}$. Sequence analysis revealed a $\beta$-agarase domain that belongs to the glycoside hydrolase family (GH) 16 and a carbohydrate-binding module (CBM_4_9) unique to agarases. AgaDL6 was heterologously expressed in Escherichia coli BL21 (DE3). Enzyme activity analysis of the purified protein showed that the optimal temperature and $\mathrm{pH}$ of AgaDL6 were $50^{\circ} \mathrm{C}$ and 3.0, respectively. AgaDL6 showed thermal stability by retaining more than $98 \%$ of activity after incubation for $2 \mathrm{~h}$ at $50^{\circ} \mathrm{C}$, a feature quite different from other agarases. AgaDL6 also exhibited outstanding acid stability, retaining $100 \%$ of activity after incubation for $24 \mathrm{~h}$ at $\mathrm{pH}$ 2.0 to 5.0, a property distinct from other agarases. This is the first agarase characterized to have such high acid stability. In addition, we observed no obvious stimulation or inhibition of AgaDL6 in the presence of various metal ions and denaturants. AgaDL6 is an exo-type $\beta-1,4$ agarase that cleaved agarose into neoagarotetraose and neoagarohexaose as the final products. These characteristics make AgaDL6 a potentially valuable enzyme in the cosmetic, food, and pharmaceutical industries.

Keywords: Agarase, GH16, CBM_4_9, eosinophilic, thermostable enzyme

\section{Introduction}

Marine red macroalgae have received increasing attention as a sustainable resource for producing fuels and fine chemicals [1, 2]. Advantages of marine red macroalgae are fast growth, high yield, low lignin content or free of lignin and growth in the sea $[3,4]$. The main carbohydrate of red macroalgae is agar which itself is composed of agarose and agaropectin. Agarose is a polysaccharide with alternating copolymers of 1-4-linked-3, 6-anhydro- $\alpha$-L-galactose and 1-3-linked $\beta$-D-galactose [5]. Agaropectin has the same framework with some hydroxyl groups of 3,6-anhydro- $\alpha-1-$ galactose residues substituted by sulfate, methoxy, or pyruvate residues [6].

Agarose is the major component of red macroalgae. A suitable method of hydrolysis is necessary to obtain oligosaccharides from agarose. At present, oligosaccharides can be produced either by chemical hydrolysis or enzymatic hydrolysis. Enzymatic hydrolysis is the first choice because it has the advantages of mild reaction conditions, product control, environmental friendliness, and high efficiency compared with chemical hydrolysis processes [7]. Agarase, which degrades agarose to oligosaccharides or monosaccharides, is important in further fermentation and microbial utilization of this compound polysaccharide [8, 9]. Agarases can be classified into $\alpha$-agarase (E.C. 3.2.1.158) and $\beta$-agarase (E.C. 3.2.1.81) according to their mode of action [2].

The $\alpha$-agarases recognize and depolymerize the $\alpha-1,3$ linkages to produce agaro-oligosaccharides with 3,6anhydro- $\alpha$-L-galactose at the reducing end. On the other hand, $\beta$-agarases recognize and cleave $\beta-1,4$ linkages to 
produce neoagaro-oligosaccharides with $\mathrm{D}$-galactose residues at the reducing ends $[10,11]$. Compared with $\alpha$-agarases, a large number of $\beta$-agarases have been found in many different genera, including Agarivorans [12], Cytophaga [13], Pseudomonas [14], Vibrio [15-17], Flammeovirga [18], and Agarivorans $[19,20]$. Based on amino acid sequence similarity, $\beta$-agarases have been classified into four distinct glycoside hydrolase (GH) families: GH16, GH50, GH86, and GH118 [21], which are recorded in the Carbohydrate-Active enZYmes Database (http://www.cazy.org). $\beta$-agarases from the GH16, GH50, GH86 families contain two major conserved modules: one a catalytic glycoside hydrolase module which is responsible for hydrolyzing of glycoside linkage and the other a non-catalytic carbohydrate binding module (CBM), which helps enzymes bind substrates by forming a substrate-binding groove [22-24].

Flammeovirga sp. HQM9, an agar-hydrolyzing marine bacterium, was isolated from the surfaces of red algae. We identified 34 complete coding sequences of agarases (all belonging to $\beta$-agarase) of Flammeovirga sp. HQM9 genome by whole-genome sequencing [25]. Of these 34 agarases, 14 belonged to the GH-16 family, 6 belonged to GH-86, and only 2 belonged to $\mathrm{GH}-50$. We predict that the remaining agarases belong to a new family.

Although a large number of agarases have been characterized in recent years, most are not resistant to acidic conditions and high temperature, which greatly limits their development and utilization. The $\beta$-agarase gene AgaDL6, being most acid- and thermostable, was cloned and characterized in this study as part of an effort to screen for more novel agarases with properties suitable for specific applications. In particular, agarase AgaDL6 had significant resistance to acidity.

\section{Materials and Methods}

\section{Bacterial Strains and Plasmids}

Flammeovirga sp. HQM9 was isolated from the surfaces of red algae and stored in our laboratory. It was cultured using $2216 \mathrm{E}$ medium $\left(2 \% \mathrm{NaCl}, 0.3 \% \mathrm{MgCl}_{2} \cdot 6 \mathrm{H}_{2} \mathrm{O}, 0.6 \% \mathrm{MgSO}_{4} \cdot 7 \mathrm{H}_{2} \mathrm{O}, 0.1 \%\right.$ $\left(\mathrm{NH}_{4}\right)_{2} \mathrm{SO}_{4}, 0.02 \% \mathrm{NaHCO}_{3}, 0.03 \% \mathrm{CaCl}_{2} \cdot 2 \mathrm{H}_{2} \mathrm{O}, 0.05 \% \mathrm{KCl}, 0.042 \%$ $\mathrm{KH}_{2} \mathrm{PO}_{4}, 0.005 \% \mathrm{NaBr}, 0.002 \% \mathrm{SrCl} \cdot 6 \mathrm{H}_{2} \mathrm{O}, 0.1 \%$ yeast extract, $0.5 \%$ tryptone) supplemented with $1.5 \%$ agar. The pMAL-p5x vector (New England Biolabs, USA) was used for cloning and expression in Escherichia coli BL21 (DE3), which were routinely incubated at $37^{\circ} \mathrm{C}$ in Luria-Bertani (LB) broth. Ampicillin $(100 \mu \mathrm{g} / \mathrm{ml})$ was added when required.

\section{Gene Cloning}

Based on the results of genome analysis of Flammeovirga sp.
HQM9, the sequence of AgaDL6 was obtained. After overnight culturing, the cell pellet of Flammeovirga sp. HQM9 was harvested, and the genomic DNA was extracted. The AgaDL6 gene was amplified by PCR using primers, forward (5-CATGCCATGGAT GAGATCATTTGTAAAGAAAAGTG-3, NcoI site is italicized) and reverse (5- ACGCGTCGACTTATTTGATTTTTTTTAGTTTAAA TG-3, SalI site is italicized). The PCR product was digested with NcoI/SalI, and then transferred into the pMAL-p5x vector, which was also digested with NcoI/SalI.

\section{Sequence Analysis and Classification of AgaDL6}

We used the BLAST program (http://www.ncbi.nlm.nih.gov/ BLAST) to search for sequence similarity and conserved domains. SignalP (version 4.1) (http://www.cbs.dtu.dk/services/ SignalP/) was utilized for the prediction of the signal peptide sequence. Then, alignment of multiple sequences was performed through ClustalW (http://www.ch. embnet.org/software/ClustalW.html). The sequence analysis was conducted using DNAMAN (Version 6.0, Lynnon Biosoft Corporation, USA).

\section{Expression and Purification of AgaDL6}

E. coli BL21 harboring pMAL-p5x- AgaDL6 was cultivated in an LB medium with ampicillin $(100 \mu \mathrm{g} / \mathrm{ml})$ at $37^{\circ} \mathrm{C}$ until a value of OD600 of 0.6 was obtained. Subsequently, induction of the culture was performed using isopropyl $\beta$-D-1-thiogalactopyranoside (IPTG; $1 \mathrm{mM}$ ), followed by further culture of the transformant at $28^{\circ} \mathrm{C}$ for $10 \mathrm{~h}$. Following centrifugation, the pellet of cells was collected and dissolved followed by sonication in $20 \mathrm{mM}$ of PBS buffer. Further, the supernatant was subjected to purification with a PurKine MBP purification system (Abbkine, China). The fractions of the elution were collected and analyzed using SDS-PAGE.

\section{Detection of Agarase Activity on Plate}

To identify the plate-based activity assay of AgaDL6, $100 \mu \mathrm{l}$ of purified AgaDL6 was put in the holes of plates containing 2\% agar, prepared in $20 \mathrm{mM}$ Tris- $\mathrm{HCl}$ buffer ( $\mathrm{pH}$ 7.0). The plates were incubated for $3 \mathrm{~h}$ at $40^{\circ} \mathrm{C}$ and then stained with Lugol's iodine solution to check for reducing sugars. The clear zone around the hole was then visualized.

\section{Assay of Enzymatic Activity of AgaDL6}

The agarase activity was determined using the 3, 5-dinitrosalicylic acid (DNS) method [26]. Briefly, $30 \mu \mathrm{l}$ of the enzymatic solution was admixed with $370 \mu \mathrm{l}$ of $20 \mathrm{mM}$ Tris- $\mathrm{HCl}$ buffer ( $\mathrm{pH}$ 7.0) with the addition of agarose $(1 \% \mathrm{w} / \mathrm{v})$, followed by incubation for $30 \mathrm{~min}$ at $40^{\circ} \mathrm{C}$. A volume of $400 \mu \mathrm{l}$ of DNS reagent solution was added to the reaction mixture, which was next subjected to boiling for $10 \mathrm{~min}$. After cooling, measurements of the absorbance were carried out at $540 \mathrm{~nm}$. Calculations of the quantities of the reduced sugars were done using D-galactose as a standard. Finally, a unit of enzyme activity was designated as the amount of enzyme able to generate $1 \mu \mathrm{mol}$ of D-galactose per minute through agarose hydrolysis. 


\section{Analysis of the Properties of Enzyme}

The effect of temperature on AgaDL6 was assayed by incubating AgaDL6 with $1 \%(\mathrm{w} / \mathrm{v})$ agarose at temperatures between $30^{\circ} \mathrm{C}$ and $70^{\circ} \mathrm{C}$ in $20 \mathrm{mM}$ Tris- $\mathrm{HCl}(\mathrm{pH} 7.0)$ for $30 \mathrm{~min}$. The effect of $\mathrm{pH}$ on AgaDL6 was determined by incubating at $40^{\circ} \mathrm{C}$ for $30 \mathrm{~min}$ in buffers with different pHs: $20 \mathrm{mM}$ sodium citrate buffer ( $\mathrm{pH} 2-6)$, $20 \mathrm{mM}$ MOPS buffer (pH 6-7), $20 \mathrm{mM}$ Tris- $\mathrm{HCl}$ buffer ( $\mathrm{pH}$ 7-9), and $20 \mathrm{mM}$ borate buffer ( $\mathrm{pH} 9-11)$. To measure the thermostability of AgaDL6, the enzyme was preincubated at various temperatures ranging from $30^{\circ} \mathrm{C}$ to $70^{\circ} \mathrm{C}$ for $2 \mathrm{~h}$, and then the residual enzyme activity was measured. The pH stability of the AgaDL6 was evaluated by pre-incubating AgaDL6 at different $\mathrm{pH}$ values (2.010.0) at optimum temperatures for different times (from 12 to $48 \mathrm{~h}$ ) and then measuring the residual enzyme activity. The relative activity was defined as a percentage with respect to the maximum agarase activity.

\section{Effects of Various Metal Ions and Reagents on Agarase Activity}

The effects of various metal ions, denaturants and chelators on AgaDL6 were investigated by measuring the enzyme activity supplemented with different concentrations $(1 \mathrm{mM}, 10 \mathrm{mM})$ of $\mathrm{Na}^{+}, \mathrm{Mn}^{2+}, \mathrm{K}^{+}, \mathrm{Mg}^{2+}, \mathrm{Zn}^{2+}, \mathrm{Ca}^{2+}, \mathrm{Ba}^{2+}, \mathrm{Cu}^{2+}, \mathrm{Co}^{2+}, \mathrm{Fe}^{3+}, \mathrm{EDTA}$, SDS and urea. All measurements were determined in triplicate. The relative activity was expressed as the percentage of activity determined with respect to the standard condition without metal ions, denaturants and chelators.

\section{Identification of Hydrolysis Products}

Thin-layer chromatography (TLC) was performed to identify hydrolysis products of AgaDL6 towards agar [25]. After incubating purified AgaDL6 with 1\% agar at different times at optimum conditions, the hydrolysis reaction was stopped by heating in a boiling water bath for $10 \mathrm{~min}$. The reaction mixture was spotted on silica gel 60 TLC plates (Merck, Germany). The plates were developed with $n$-butanol-acetic acid-water (2:1:1 by volume) solution. Spots were visualized by spraying with $20 \%$ $\mathrm{H}_{2} \mathrm{SO}_{4}$ in methanol and heating at $120^{\circ} \mathrm{C}$ for 2 min. Neoagarobiose (NA2), neoagarotetraose (NA4), neoagarohexaose (NA6), neoagarooctaose (NA8) and neoagarodecaose (NA10) were used as standards. The molecular mass of the enzymatic products was determined using a matrix-assisted laser desorption ionization time-of-flight (MALDI-TOF) mass spectrometer (AB Sciex, USA). The matrix for all samples was 2,5-dihydroxybenzoic acid (DHB) $(10 \mathrm{mg} / \mathrm{ml} \mathrm{DHB}$ in $30 / 70$ acetonitrile/water with $0.1 \%$ TFA final concentration) and the ratio of the sample and matrix was 1:1. The measured data were analyzed and exported using Data Explorer Software 4.11 (AB Sciex).

\section{Nucleotide Sequence Accession Number}

The nucleotide sequence of AgaDL6 in strain Flammeovirga sp. HQM9 has been submitted to the GenBank database under accession number WP010523251. The draft genome sequence of HQM9 is available in GenBank under accession number AFPB00000000.

\section{Results}

\section{Sequence Analysis}

After PCR amplification using specific primers, the agarase gene was obtained and named AgaDL6. Sequence analysis showed that agarase gene AgaDL6 consists of $1,383 \mathrm{bp}$, encoding a protein of 461 amino acids with an estimated molecular mass of $52.8 \mathrm{kDa}$ and a $\mathrm{pI}$ of 6.15. The search for conserved domains of AgaDL6 was performed according to the NCBI Conserved Domain Search. The result showed that AgaDL6 has two conserved domains: a glycoside hydrolase family 16 (GH16) catalytic module comprising 253 amino acids (Pro71-Arg323) in the Nterminal, and a carbohydrate-binding module 4_9 (CBM_4_9) comprising 72 amino acids (Gly333- Ala404) in the Cterminal (Fig. 1A).

Moreover, the amino acids of AgaDL6 showed high homology with $\beta$-agarases in the NCBI database: $86 \%$ to the $\beta$-agarase from Aquimarina agarilytica (GenBank Accession No. WP_010177128), 61\% to the $\beta$-agarase from Aquimarina agarilytica (GenBank Accession No. WP_010177127), 55\% to the $\beta$-agarase from Aquimarina agarivorans (GenBank Accession No. WP_ 010523252), and 55\% to the $\beta$-agarase from Echinicola strongylocentroti (GenBank Accession No. WP_112786421). Multiple sequence alignments of AgaDL6 with known $\beta$-agarases were performed and the conserved catalytic residues were also analyzed (Fig. 1B). Based on the sequence homology between AgaDL6 and these members of GH16 family, we presumed that the amino acids of the active sites in AgaDL6 were Glu-182 and Glu187 as the nucleophile and the acid/base, respectively [27]. The third catalytic site, the acidic amino acid residue Asp-185, may be related to maintenance of the charge environment during the interaction of the enzyme with the substrate [28].

\section{Purification of AgaDL6 and Agarase Activity Assay}

The $\beta$-agarase gene AgaDL6 was cloned into a pMal-p5x expression vector by fusion with a MBP at the N-terminal. The fusion protein pMal-AgaDL6 was purified to homogeneity by amylose resin under the induction of $1 \mathrm{mM}$ IPTG. The purified AgaDL6 was observed as a single band on SDS-PAGE. Its molecular mass was estimated to be $95 \mathrm{kDa}$, matching the calculated size of AgaDL6 (52.8 kDa) with the MBP-tag (42.5 kDa) (Fig. 2A). In addition, a platebased activity assay illustrated that purified AgaDL6 showed an obvious hydrolysis cycle on agar plates after a 3-h incubation (Fig. 2B), which initially demonstrated the agarase activity of AgaDL6. 


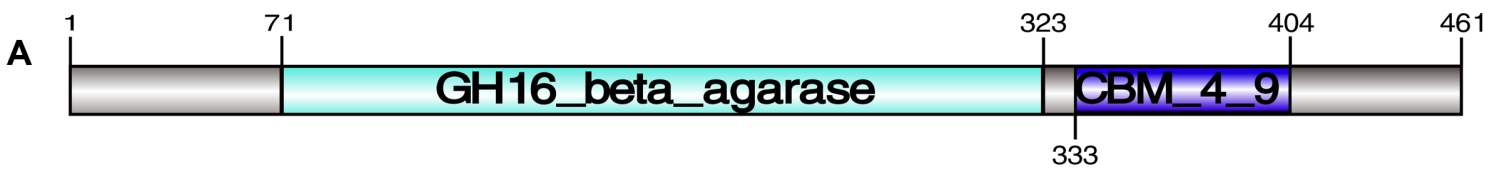

B

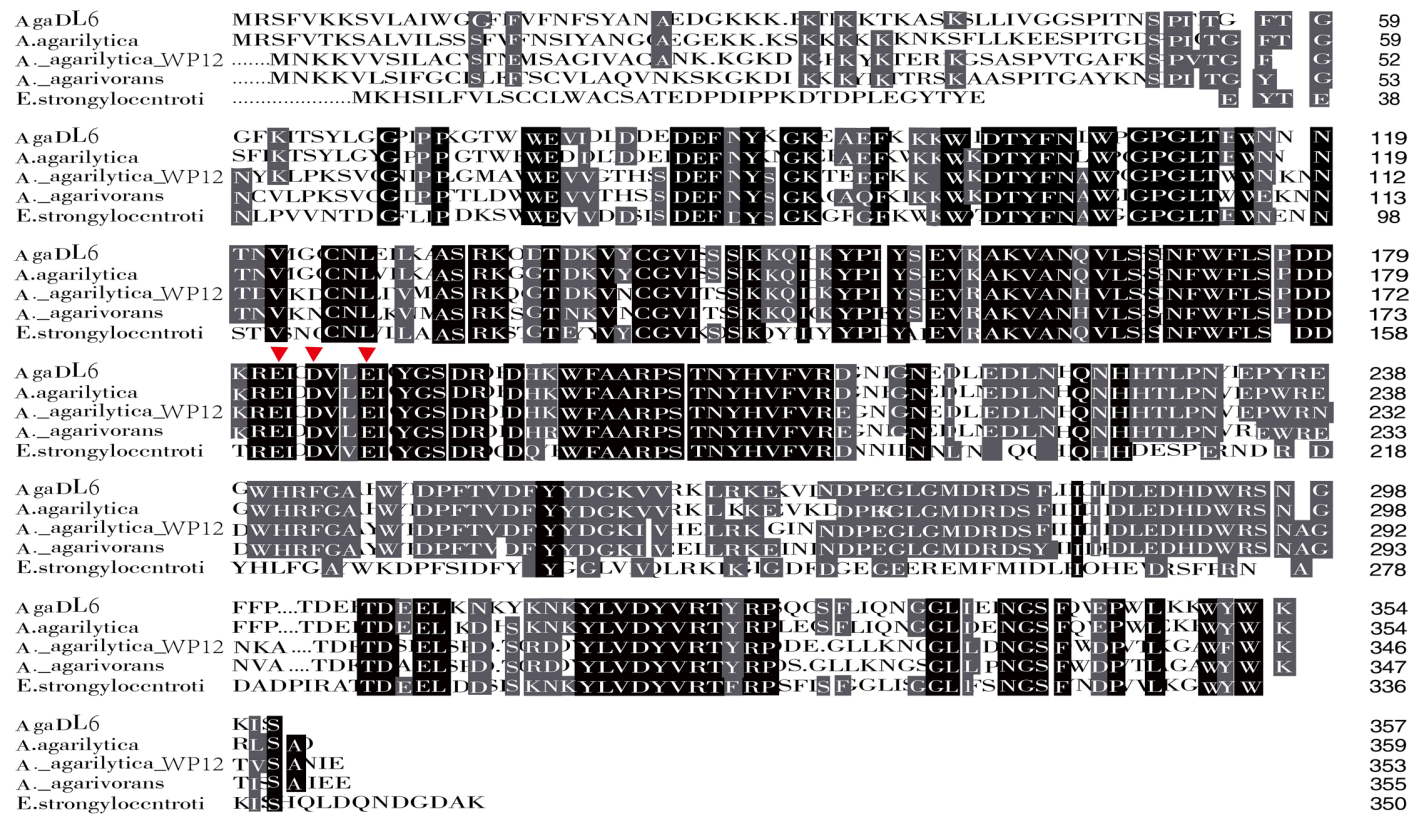

Fig. 1. Sequence properties of the agarase AgaDL6.

(A) Domain structure of AgaDL6. GH16, glycoside hydrolase module of family 16; CBM_4_9, family_4_9 carbohydrate-binding module. The amino acid numbers of each module (domain) are indicated. (B) Multiple sequence alignments of the catalytic domain in AgaDL6 with other known $\beta$-agarases belonging to GH16 family. The predicted catalytic residues of AgaDL6 (Glu-182, Asp-184, and Glu-187) are highlighted as solid inverted triangle symbols.

\section{Biochemical Analysis of Agarase}

The effect of temperature on agarase activity of AgaDL6 was determined by incubating purified AgaDL6 at different temperatures $\left(30^{\circ} \mathrm{C}\right.$ to $\left.70^{\circ} \mathrm{C}\right)$. The purified AgaDL6 exhibited maximum agarase activity at $50^{\circ} \mathrm{C}$. AgaDL6 maintained more than $87 \%$ of its activity over a wide temperature range $\left(40^{\circ} \mathrm{C}\right.$ to $\left.60^{\circ} \mathrm{C}\right)$. The enzymatic activity of AgaDL6 reduced sharply at $65^{\circ} \mathrm{C}$, while $59 \%$ of its maximal activity was still maintained (Fig. 2D). Even after pre-incubation at $50^{\circ} \mathrm{C}$ or lower for $2 \mathrm{~h}$, the agarase activity of AgaDL6 was maintained at almost $98 \%$ of its initial activity. The enzyme retained $84 \%$ of residual activities after incubation at $60^{\circ} \mathrm{C}$ for $2 \mathrm{~h}$. When the pre-incubation temperature was raised to $65^{\circ} \mathrm{C}$, the AgaDL6 activity was reduced to less than $25 \%$ of its initial activity.

In addition, as shown in Fig. 2C, the effect of $\mathrm{pH}$ on AgaDL6 activity was assayed by incubating AgaDL6 with agarose $(1 \%, \mathrm{w} / \mathrm{v})$ at different $\mathrm{pH}$ values (2 to 11$)$. The results revealed that the optimal reaction $\mathrm{pH}$ of AgaDL6 was $\mathrm{pH} 3$, and AgaDL6 exhibited strong stability across a wide range of $\mathrm{pH}(2-7)$. AgaDL6 maintained approximately $96 \%$ of its maximum activity across a range of $\mathrm{pH}$ (2 to 5) (Fig. 2C). Notably, AgaDL6 possesses excellent stability in the range of $\mathrm{pH}$ from $2.0-5.0$ and retains $100 \%$ of activity after incubating for $24 \mathrm{~h}$, saving approximately $90 \%$ activity even after $36 \mathrm{~h}$ incubation at the $\mathrm{pH}$ range mentioned above (Fig. 2E). Meanwhile, less than $40 \%$ of residual activity was retained after $24 \mathrm{~h}$ or longer incubation at $\mathrm{pH}$ values ranging from 7.0 to 10.0, proving that AgaDL6 is an acidic agarase.

\section{Effects of Various Metal Ions and Reagents on the Activity of AgaDL6}

The effects of different metal ions and reagents on AgaDL6 activity were investigated by using various metal ions and reagents at final concentrations of 1 or $10 \mathrm{mM}$. The AgaDL6 activities were stable in conditions with $10 \mathrm{mM}$ macroelements contained in seawater, such as $\mathrm{Na}^{+}, \mathrm{K}^{+}$, and $\mathrm{Mg}^{2+}$ (Table 1). $\mathrm{Ca}^{2+}$ at $1 \mathrm{mM}$ had no effect on AgaDL6 activity, but showed a slight positive effect at $10 \mathrm{mM}$. The 
A

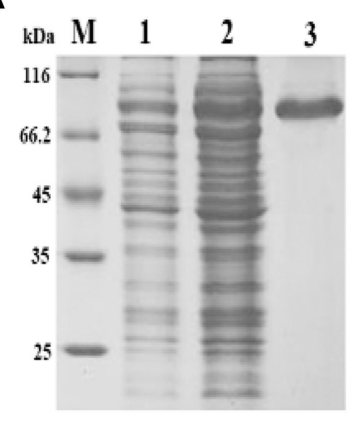

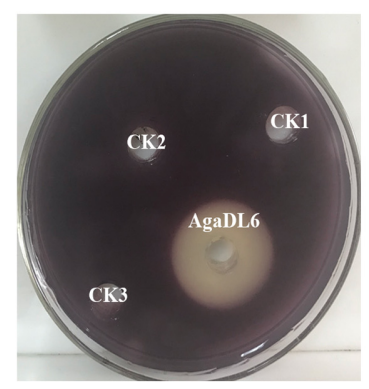

C

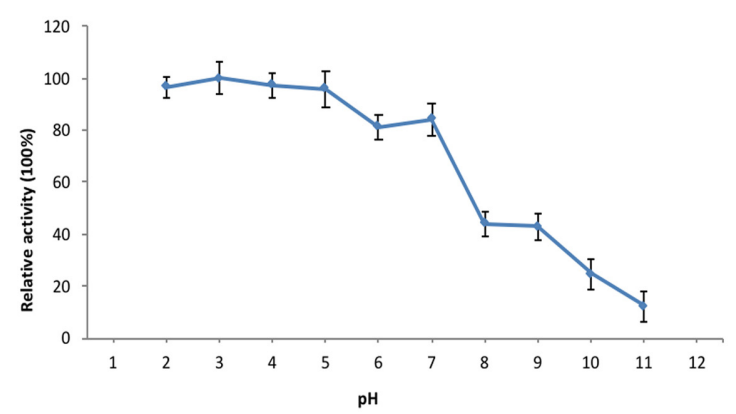

E

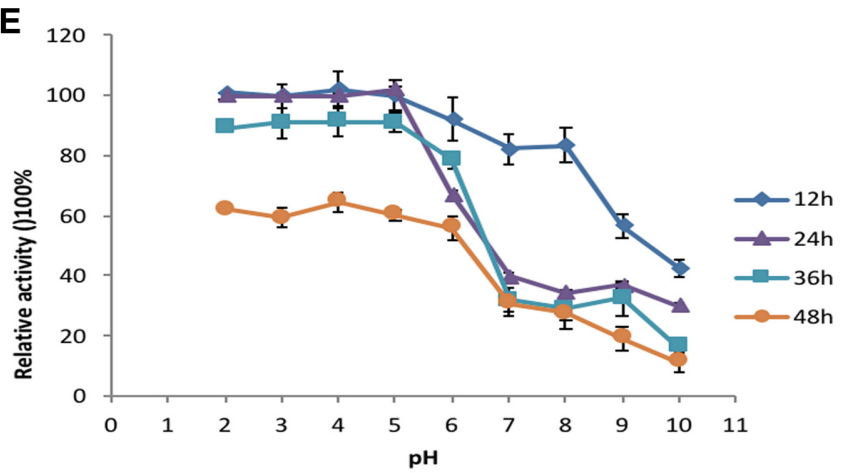

Fig. 2. Purification and biochemical characteristics of the agarase AgaDL6.

(A) SDS-PAGE analysis of purified recombinant AgaDL6. Lines: M, protein marker; 1, uninduced recombinant E. coli BL21 cells harboring pMALAgaDL6; 2, recombinant E. coli BL21 cells harboring pMAL-AgaDL6 after induced; 3, purified AgaDL6. (B) Examination of AgaDL6 activity with Lugol's iodine solution. AgaDL6, purified AgaDL6; Ck1, uninduced E. coli BL21 cells harboring pMAL; Ck2, induced E. coli BL21 cells harboring pMAL; Ck3, uninduced E. coli BL21 cells harboring pMAL-AgaDL6. (C) Effects of pH on activity of AgaDL6. (D) Effects of temperature on activity and stability of AgaDL6. (E) pH stability of AgaDL6. Data are mean \pm SD of three independent experiments.

agarase AgaDL6 basically retained full activity after treatment with $1 \mathrm{mM}$ and $10 \mathrm{mM}$ each of heavy metal ions such as $\mathrm{Ba}^{2+}, \mathrm{Co}^{2+}, \mathrm{Fe}^{3+}, \mathrm{Zn}^{2+}$, and $\mathrm{Cu}^{2+}$ ion. Meanwhile, the activity of AgaDL6 was slightly reduced by a high concentration of EDTA $(10 \mathrm{mM})$, whereas a low concentration of EDTA, SDS and urea had a slight positive effect on the activity of AgaDL6.

\section{Oligosaccharide Degradation Patterns of AgaDL6}

An analysis of the hydrolysis pattern and products of agarase AgaDL6 was done to determine whether AgaDL6 was an endo- or exo-glycoside hydrolase, as well as to clarify its final hydrolysis products. A time course hydrolysis analysis was performed with the purified AgaDL6. The TLC analysis of the final products showed that AgaDL6 hydrolysed agarose into two predominate products, including neoagarotetraose (NA4), and neoagarohexaose (NA6) according to the standards (Fig. 3A). In the early stage of the reaction, agarose was rapidly degraded to NA4 and NA6. No neoagaro-oligosaccharides larger than NA6 were observed even after a long incubation of $24 \mathrm{~h}$. Meanwhile, the results revealed that the amounts of NA4 and NA6 increased with the prolongation of the hydrolysis time, indicating that AgaDL6 has the characteristics of an exohydrolase.

We concluded that AgaDL6 is an exo-type $\beta$-agarase because of the NA4 and NA6 products. This speculation was further validated by TLC analysis using NA2, NA4, NA6, neoagaro-octaose (NA8) and neoagarodecaose (NA10) as a substrate (Fig. 3B). As shown in Fig. 3B, AgaDL6 could not hydrolyze NA2, NA4 and NA6. Whereas NA8 was completely hydrolyzed to NA4 and NA10 was digested to produce NA6 and NA4 by cleavage of the $\beta-1,4$ glycoside linkage. NA8 was the smallest oligosaccharide that AgaDL6 could hydrolyze and NA4 was the minimal oligosaccharide product.

To determine the exact masses of the hydrolysis products of AgaDL6, MALDI-TOF/TOF MS analysis was performed 
Table 1. Effects of various metal ions and chemical reagents on the activity of AgaDL6.

\begin{tabular}{lcc}
\hline & \multicolumn{2}{c}{ Relative activity $(100 \%)$ of AgaDL6 } \\
\cline { 2 - 3 } Reagents & $1 \mathrm{mM}$ & $10 \mathrm{mM}$ \\
\hline $\mathrm{Control}$ & $100 \pm 0.3$ & $100 \pm 0.3$ \\
$\mathrm{NaCl}$ & $103 \pm 0.4$ & $105 \pm 0.5$ \\
$\mathrm{KCl}$ & $102 \pm 0.3$ & $99 \pm 0.2$ \\
$\mathrm{CaCl}_{2}$ & $101 \pm 0.4$ & $117 \pm 0.5$ \\
$\mathrm{BaCl}_{2}$ & $113 \pm 0.3$ & $112 \pm 0.4$ \\
$\mathrm{MgCl}_{2}$ & $107 \pm 0.5$ & $109 \pm 0.4$ \\
$\mathrm{CuCl}_{2}$ & $103 \pm 0.1$ & $98 \pm 0.2$ \\
$\mathrm{ZnCl}_{2}$ & $102 \pm 0.3$ & $111 \pm 0.3$ \\
$\mathrm{MnCl}_{2}$ & $91 \pm 0.4$ & $93 \pm 0.2$ \\
$\mathrm{FeCl}_{3}$ & $99 \pm 0.1$ & $93 \pm 0.3$ \\
$\mathrm{CoCl}_{2}$ & $97 \pm 0.3$ & $108 \pm 0.6$ \\
$\mathrm{SDS}_{\mathrm{EDTA}}$ & $110 \pm 0.5$ & $91 \pm 0.3$ \\
$\mathrm{Urea}$ & $106 \pm 0.4$ & $89 \pm 0.3$ \\
\hline
\end{tabular}

${ }^{a}$ The enzymatic activity with no metal ions, chelators or denaturants was set as $100 \%$.

${ }^{\mathrm{b}}$ Values represent the means \pm standard deviation (SD) $(n=3)$.

(Fig. 3C). MALDI-TOF mass spectra revealed that the major products have molecular ions at $\mathrm{m} / \mathrm{z}$ of $653(\mathrm{M}+\mathrm{Na})^{+}, 669$ $(\mathrm{M}+\mathrm{K})^{+}, 959(\mathrm{M}+\mathrm{Na})^{+}$, and $975(\mathrm{M}+\mathrm{K})^{+}$. These peaks were attributed to NA4 and NA6, respectively. Combining these results, the main end products of AgaDL6 were NA4 and NA6.

\section{Discussion}

Bacteria of the Flammeovirga genus have recently been identified from the surface of algae [18], deep-sea and coastal sediments [29], and the digestive tract of marine animals [30]. In our efforts to screen agar-hydrolyzing bacteria, a new agar-degrading bacterium, Flammeovirga sp. HQM9, was isolated from the surfaces of red algae. The genome of HQM9 was sequenced [25]. A new agarase gene AgaDL6 was screened and overexpressed in E. coli. The catalytic module of AgaDL6 contained three conserved characteristic motifs, DEFNY, EIDVLE and VDYVR at catalytically active sites and at calcium-binding regions [27], which were highly homologous to the conserved sequence of the GH16 catalytic motif [17].

The search for a conserved domain of AgaDL6 showed that the sequence in the $\mathrm{N}$-terminal region was a betaagarase domain belonging to the GH family 16; the protein did not contain the same C-terminal carbohydrate-binding module 6 (CBM6) module as previously reported for other GH16 members [31, 32]. All agarases reportedly contain a glycoside hydrolase domain, which is responsible for hydrolyzing the glycoside linkage and a carbohydratebinding module (CBM), which helps enzymes bind substrates by forming a substrate-binding groove [23]. CBMs are generally classified into 71 families based on the similarity of amino acid sequences. At present, only CBM6 and CBM13 have been found in agarases [33]. Analysis using the CAZy and SMART databases suggested that AgaDL6 contained only one CBM_4_9 (Gly333 to Ala404) (Fig. 1A). This is significantly different from other GH16 members with CBM6 [33]. Although AgaDL6 belongs to a member of the GH16 family, our results show that it is different from the other members and thus a novel agarase belonging to the GH16 family obtained from bacteria of the genus Flammeovirga. The presence of CBM_4_9 in AgaDL6 is particularly interesting. The CBM likely functions as a dominant module that contributes to the special characteristics of AgaDL6.

Industrial processing requires an agarase with high stability and activity at temperatures above the gelling temperature of agar (about $40^{\circ} \mathrm{C}$ ) [34]. Thermostability is important in the enzymatic conversion of agar or seaweed [28]. Since agarases come from the marine environment, a low temperature environment, most of them lose their activity at high temperatures, which greatly restricts the application of agarase [35, 36]. However, AgaDL6 exhibited thermostability during pre-incubation at $60^{\circ} \mathrm{C}$ for $2 \mathrm{~h}$. These results indicate that agarase AgaDL6 has good thermostability. In this report, the stable and optimum temperatures of AgaDL6 are higher than the gelling temperature of agar.

AgaDL6 demonstrated maximum activity at $\mathrm{pH}$ 3.0. It is well known that natural seawater has a weak basic $\mathrm{pH}$ value so most agarases have been reported to exhibit optimum activity at a neutral $[36,37]$ or a weak basic $\mathrm{pH}$ $[20,38]$. Rarely, agarase exhibits maximum activity under these conditions. Furthermore, AgaDL6 maintained approximately $95 \%$ of its maximum activity from $\mathrm{pH} 2$ to 5 . It is worth noting that AgaDL6 was extremely stable at these conditions, retaining $100 \%$ of activity even after $24 \mathrm{~h}$ of treatment at a $\mathrm{pH}$ range of $\mathrm{pH}$ 2.0-5.0, which reflects more acid resistance than other agarases.

The high degree of polymerization of agarose and the tendency to form a gel seriously hinder the hydrolysis of agarase [39]. Therefore, to efficiently obtain fermentable sugars from agarose, a chemical pretreatment such as acid 

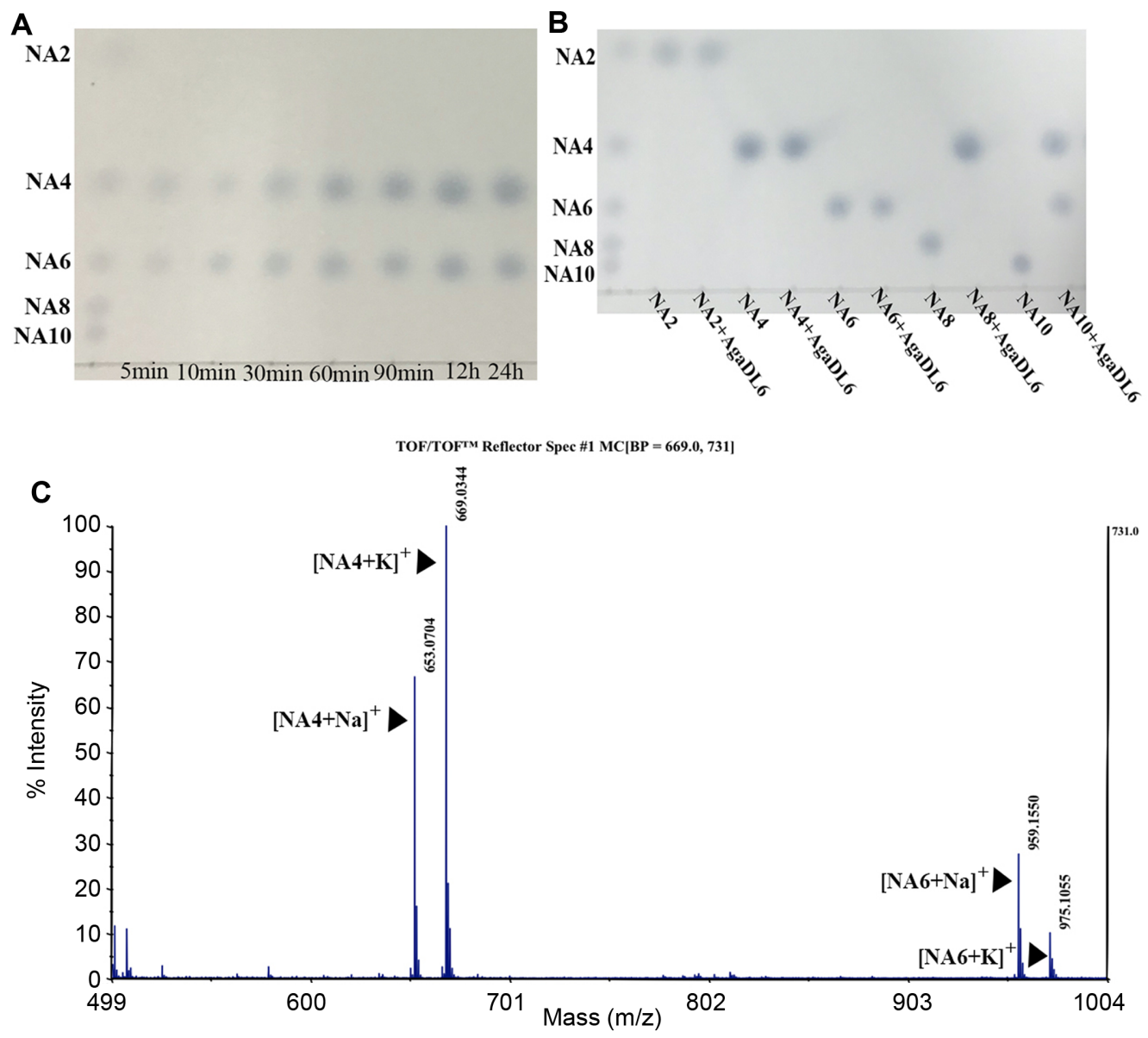

Fig. 3. Polysaccharide degradation pattern of the agarase AgaDL6.

(A) TLC analysis of agar degradation by AgaDL6 at different times. (B) TLC analysis of the catalytic property against the oligosaccharide. Neoagarobiose (NA2), neoagarotetraose (NA4), neoagarohexaose (NA6), neoagarooctaose (NA8) and neoagarodecaose(NA10) were used as standards. (C) MALDI-TOF mass result of the end products.

pretreatment can increase the enzymatic efficiency of agarose [40,41]. Enzymatic hydrolysis combined with acid treatment can increase the yield of reducing sugar [42]. However, the high concentration of acid used in the acid pretreatment adversely affects the subsequent enzymatic reaction because known agarases are acid intolerant so an additional neutralization reaction is required. Similarly, the high salt concentration formed during the neutralization process also affects the subsequent enzymatic reaction [43]. These bottlenecks can be avoided by use of an acidresistant acidic agarase, such as AgaDL6.

We also found that metals ions did not significantly activate or inhibit AgaDL6 activity. The activity of AgaDL6 was hardly influenced by $1 \mathrm{mM}$ EDTA, and was only slightly inhibited by $10 \mathrm{mM}$ EDTA, indicating that AgaDL6 is not a metal-ion dependent enzyme. Catalytic activity might not require the participation of divalent metal ions.
This is a favorable property for industrial applications.

The hydrolysis pattern showed only two spots or peaks in both TLC and MALDI-TOF MS analysis: the amounts of two products increased with increasing reaction time, and no other oligosaccharides were observed during the enzymatic reaction. This hydrolysis pattern indicates there is no reaction intermediate such as NA8 or NA10 during the hydrolysis process, which is the classic hydrolysis mode of exo-agarases [20,38]. In contrast, endo-agarase hydrolyzed agarose in a sort of random cleavage yielded oligosaccharides with different degrees of polymerization during the hydrolysis procedure [10]. As only two products were observed during enzymatic reaction and there was no change in the hydrolysis pattern, AgaDL6 was identified as an exo-type agarase.

AgaDL6 depolymerizes agarose into NA4 and NA6 as final products. This is distinct from most exo-agarases, 
which produce only one type of oligosaccharide as the final product $[44,45]$. The primary structure of the agarase determines its function and will ultimately affect its final products. Sequence analysis of AgaDL6 indicated that it has a special CBM_4_9 structure; therefore, the catalytic mechanism of AgaDL6 may be different from other agarases. Compared to an endolytic pattern, exo-type agarases reduce the complexity of oligosaccharide purification and the costs of product recovery by usually producing only two or fewer end product oligosaccharides. This is an obvious advantage in industrial applications.

In summary, AgaDL6 has these unique characteristics: outstanding acid resistance and stability, thermostability, high adaptability to high ion concentrations and simple hydrolysis products. Even after $24 \mathrm{~h}$ of treatment at a $\mathrm{pH}$ range of pH 2.0-5.0, AgaDL6 retained stability, unlike any other agarase. The high thermostability at temperatures higher than the gelatinization temperature has prospects for broad application in the enzymatic conversion of agar or seaweed. Catalytic activity might not require the participation of divalent metal ions. The reduced complexity of oligosaccharide purification reduces the costs of product recovery. These characteristics are important advantages for further industrial application compared with other agarases.

\section{Acknowledgments}

This work was supported by the National Natural Science Foundation of China (21506116). We thank Xiaoxu Tian and Dr. Chao Peng of the Mass Spectrometry System at the National Facility for Protein Science in Shanghai (NFPS), Zhangjiang Lab, China, for providing technical support and assistance in data collection and analysis.

\section{Conflict of Interest}

The authors have no financial conflicts of interest to declare.

\section{References}

1. Singh A, Nigam PS, Murphy JD. 2011. Renewable fuels from algae: an answer to debatable land based fuels. Bioresour. Technol. 102: 10-16.

2. Yun EJ, Kim HT, Cho KM, Yu S, Kim S, Choi IG, et al. 2016. Pretreatment and saccharification of red macroalgae to produce fermentable sugars. Bioresour. Technol. 199: 311-318.

3. Wargacki AJ, Leonard E, Win MN, Regitsky DD, Santos CN, Kim PB, et al. 2012. An engineered microbial platform for direct biofuel production from brown macroalgae. Science 335: 308-313.

4. Song T, Xu H, Wei C, Jiang T, Qin S, Zhang W, Cao Y, et al. 2016. Horizontal transfer of a novel soil agarase gene from marine bacteria to soil bacteria via human microbiota. Sci. Rep. 6: 1-10.

5. Hehemann JH, Correc G, Thomas F, Bernard T, Barbeyron T, Jam M, et al. 2012. Biochemical and structural characterization of the complex agarolytic enzyme system from the marine bacterium Zobellia galactanivorans. J. Biol. Chem. 287: 3057130584 .

6. Dong $\mathrm{Q}$, Ruan LW, Shi H. 2016. A $\beta$-agarase with high $\mathrm{pH}$ stability from Flammeovirga sp. SJP92. Carbohydr. Res. 432: 1-8.

7. Chi WJ, Chang YK, Hong SK. 2012. Agar degradation by microorganisms and agar-degrading enzymes. Appl. Microbiol. Biotechnol. 94: 917-930.

8. Zhang WB, Xu JN, Liu D Liu H, Lu XZ, Yu WG. 2018. Characterization of an $\alpha$-agarase from Thalassomonas $\mathrm{sp}$. LD5 and its hydrolysate. Appl. Microbiol. Biotechnol. 102: 2203-2212.

9. Ramos KRM, Valdehuesa KNG, Nisola GM, Lee WK, Chung WJ. 2018. Identification and characterization of a thermostable endolytic $\beta$-agarase Aga2 from a newly isolated marine agarolytic bacteria Cellulophaga omnivescoria W5C. New Biotechnol. 40: 261-267.

10. Jung S, Lee CR, Chi WJ, Bae CH, Hong SK. 2017. Biochemical characterization of a novel cold-adapted GH39 beta-agarase, AgaJ9, from an agar-degrading marine bacterium Gayadomonas joobiniege G7. Appl. Microbiol. Biotechnol. 101: 1965-1974.

11. Araki C. 1959. Seaweed polysaccharides. pp 15-30. In: Wolfrom ML (ed) Carbohydrate chemistry of substances of biological interests. Pergamon Press, London.

12. Lin B, Lu G, Zheng Y, Xie W, Li S, Hu Z. 2012. Gene cloning, expression and characterization of a neoagarotetraoseproducing beta-agarase from the marine bacterium Agarivorans sp. HZ105. World J. Microbiol. Biotechnol. 28: 1691-1697.

13. van der Meulen HJ, Harder W. 1976. Characterization of the neoagarotetraase and neoagarobiase of Cytophaga flevensis. Antonie van Leeuwenhoek 42: 81-94.

14. Morrice LM, McLean MW, Long WF, Williamson FB. 1983. $\beta$-Agarases I and II from Pseudomonas atlantica. Substrate specificities. Eur. J. Biochem. 137: 149-154.

15. Fu W, Han B, Duan D, Liu W, Wang C. 2008. Purification and characterization of agarases from a marine bacterium Vibrio sp. F-6. J. Ind. Microbiol. Biotechnol. 35: 915-922.

16. Liao L, Xu XW, Jiang XW, Cao Y, Yi N, Huo YY, et al. 2011. Cloning, expression, and characterization of a new betaagarase from Vibrio sp. strain CN41. Appl. Environ. Microbiol. 77: 7077-7079.

17. Dong J, Tamaru Y, Araki T. 2007. A unique beta-agarase, AgaA, from a marine bacterium, Vibrio sp. strain PO-303. Appl. Microbiol. Biotechnol. 74: 1248-1255. 
18. Yang JI, Chen LC, Shih YY, Hsieh C, Chen CY, Chen WM, et al. 2011. Cloning and characterization of $\beta$-agarase AgaYT from Flammeovirga yaeyamensis strain YT. J. Biosci. Bioeng. 112: 225-232.

19. Long $\mathrm{M}, \mathrm{Yu} Z \mathrm{Z}, \mathrm{Xu}$ X. 2010. A novel $\beta$-agarase with high $\mathrm{pH}$ stability from marine Agarivorans sp. LQ48. Mar. Biotechnol. 12: 62-69.

20. Ohta Y, Hatada Y, Miyazaki M, Nogi Y, Ito S, Horikoshi K. 2005. Purification and characterization of a novel $\alpha$-agarase from a Thalassomonas sp. Curr. Microbiol. 50: 212-216.

21. Tawara M, Sakatoku A, Tiodjio RE, Tanaka D, Nakamura S. 2015. Cloning and characterization of a novel agarase from a newly isolated bacterium Simiduia sp. Strain TM-2 able to degrade various seaweeds. Appl. Biochem. Biotechnol. 177: 610-623.

22. Fu X, Kim S. 2010. Agarases: review of major sources, categories, purification method, enzyme characteristics and application. Mar. Drugs. 8: 200-218.

23. Boraston AB, Bolam DN, Gilbert HJ, Davies GJ. 2004. Carbohydrate-binding modules: fine-tuning polysaccharide recognition. Biochem. J. 382: 769-781.

24. Ekborg N, Taylor L, Weiner R, Hutcheson S. 2006. Genomic and proteomic analysis of the agarolytic system of Saccharophagus degradans strain 2-40. Appl. Environ. Microbiol. 72: 3396-3405.

25. Du ZJ, Zhang ZW, Miao TT. 2011. Draft Genome sequence of the novel agar-digesting marine bacterium HQM9. J. Bacteriol. 193: 4557-4558.

26. Chi WJ, Park DY, Seo YB, Chang YK, Lee SY, Hong SK. 2014. Cloning, expression, and biochemical characterization of a novel GH16 $\beta$-agarase AgaG1 from Alteromonas sp. GNUM-1. Appl. Microbiol. Biotechnol. 98: 4545-4555.

27. McCarter JD, Withers SG. 1994. Mechanisms of enzymatic glycoside hydrolysis. Curr. Opin. Struct. Biol. 4: 885-892.

28. Mai ZM, Su HF, Zhang S. 2016. Isolation and Characterization of a glycosyl hydrolase family $16 \beta$-Agarase from a mangrove soil metagenomic library. Int. J. Mol. Sci. 17: 1-12.

29. Xu H, Fu Y, Yang N, Ding Z, Lai Q, Zeng R. 2012. Flammeovirga pacifica sp. nov., isolated from deep-sea sediment. Int. J. Syst. Evol. Microbiol. 62: 937-941.

30. Zhao J, Shi B, Jiang QR, Ke CH. 2012. Changes in gutassociated flora and bacterial digestive enzymes during the development stages of abalone (Haliotis diversicolor). Aquaculture 343: 147-153.

31. Fu XT, Pan $\mathrm{CH}$, Lin $\mathrm{H}, \mathrm{Kim}$ SM. 2009. Gene cloning, expression, and characterization of a $\beta$-Agarase, AgaB34, from Agarivorans albus YKW-34. J. Microbiol. Biotechnol. 19: 257-264.

32. Henshaw J, Horne-Bitschy A, van Bueren AL. 2006. Family 6 carbohydrate binding modules in beta-agarases display exquisite selectivity for the non-reducing termini of agarose chains. J. Biol. Chem. 281: 17099-17107.

33. Alkotaini B, Han NS, Kim BS. 2016. Enhanced catalytic efficiency of endo- $\beta$-agarase I by fusion of carbohydratebinding modules for agar prehydrolysis. Enzyme Microbial. Technol. 9: 142-149.

34. Ohta Y, Hatada Y, Nogi Y. 2004. Enzymatic properties and nucleotide and amino acid sequences of a thermostable $\beta$ agarase from a novel species of deep-sea microbulbifer. Appl. Microbiol. Biotechnol. 64: 505-514.

35. Hu Z, Lin BK, Xu Y, Zhong MQ, Liu GM. 2008. Production and purification of agarase from a marine agarolytic bacterium Agarivorans sp. HZ105. J. Appl. Microbiol. 106: 181-190.

36. Vera J, Alvarez R, Murano E, Slebe JC, Leon O. 1998. Identification of a marine agarolytic Pseudoalteromonas isolate and characterization of its extracellular agarase. Appl. Environ. Microbiol. 64: 4378-4383.

37. Wang JX, Mou HJ, Jiang XL, Guan HS. 2006. Characterization of a novel $\beta$-agarase from marine Alteromonas sp. SY37-12 and its degrading products. Appl. Microbiol. Biotechnol. 71: 833-839.

38. Fu XT, Lin H, Kim SM. 2008. Purification and characterization of a novel $\beta$-agarase, AgaA34, from Agarivorans albus YKW34. Appl. Microbiol. Biotechnol. 78: 265-273.

39. Kim JH, Yun EJ, Seo N, Yu S, Kim DH, Cho KM, et al. 2017. Enzymatic liquefaction of agarose above the sol-gel transition temperature using a thermostable endo-type $\beta$ agarase, Aga16B. Appl. Microbiol. Biotechnol. 101: 1111-1120.

40. Kim HT, Lee S, Kim KH, Choi IG. 2012. The complete enzymatic saccharification of agarose and its application to simultaneous saccharification and fermentation of agarose for ethanol production. Bioresour. Technol. 107: 301-306.

41. Yun EJ, Lee S, Kim JH, Kim BB, Kim HT, Lee SH, et al. 2013. Enzymatic production of 3,6-anhydro-l-galactose from agarose its purification and in vitro skin-whitening anti-inflammatory activities. Appl. Microbiol. Biotechnol. 97: 2961-2970.

42. Kim SW, Hong CH, Jeon SW, Shin HJ. 2015. High-yield production of reducing sugars from Gracilaria verrucosa by acid and enzymatic hydrolysis processes. Bioresour. Technol. 196: 634-641.

43. Rios G, Ferrando A, Serrano R. 1997. Mechanisms of salt tolerance conferred by overexpression of the HAL1 Gene in Saccharomyces cerevisiae. Yeast 13: 515-528.

44. Liu N, Mao X, Du Z, Mu B, Wei D. 2014. Cloning and characterization of a novel neoagarotetraose forming betaagarase, AgWH50A from Agarivorans gilvus WH0801. Carbohydr. Res. 388: 147-151.

45. Li J, Hu Q, Li Y, Xu Y. 2015. Purification and characterization of cold-adapted beta-agarase from an Antarctic psychrophilic strain. Braz. J. Microbiol. 46: 683-690. 